\title{
As Práticas de Responsabilidade Social Empresarial Relatadas nos Artigos Científicos dos Eventos da ANPAD no Período de 2002-2012
}

\section{The Corporate Social Responsibility Practices Reported in Scientific Articles of Events ANPAD the Period 2002-2012}

\author{
Cassileide Leonel da Silva \\ Graduada em administração pela Faculdade Boa Viagem \\ Endereço: Rua Itaipu, 80,Santa Mônica, Camaragibe/Pernambuco, CEP: 54.767-378, Fone (81) 8595- \\ 8440. E-mail: kacy adm@hotmail.com.
}

Ana Paula Ferreira da Silva

Contadora, Mestra em Administração pelo Programa de Pós-graduação em Administração

(PROPAD)/UFPE. Professora da Faculdade Boa Viagem e da Faculdade Santa Catarina.

Endereço: Rua do Riachuelo, 325/705, Boa Vista, Recife/Pernambuco, CEP: 50.050-400, Fone (81) 8832-

4121. E-mail: anapafesilva@hotmail.com.

\begin{abstract}
James Anthony Falk
Pós-Doutor pela Medical College of Virginia. Professor do Mestrado em Administração Empresarial da Faculdade Boa Viagem.

Endereço: Rua Professor Júlio Ferreira de Melo, 45/602, Boa Viagem, Recife/Pernambuco, CEP: 51.020230, Fone (81) 9172-4163. E-mail: thefalks@terra.com.br
\end{abstract}

\section{RESUMO}

Este trabalho objetiva identificar e analisar as práticas de Responsabilidade Social (RS) adotadas por entidades brasileiras e narradas nos estudos encontrados nos eventos da Associação Nacional de Pós-Graduação e Pesquisa em Administração (ANPAD), no período de 2002 a 2012. A amostra deste estudo foi composta por 30 (trinta) artigos tratando de experiências empresariais sobre RS durante o período de estudo. As descobertas evidenciaram que: a) ocorreu uma possível mudança de postura, pois anteriormente, as corporações direcionavam boa parte das ações sociais para os seus colaboradores, e presentemente, buscam estratégias com inclusão de ações para a sociedade e o meio ambiente nesse processo; b) há uma busca, pelas organizações, de mais parcerias com o governo, a nível estadual e municipal, uma vez que procuram atuar nas regiões próximas às suas instalações; e c) o foco dos gestores em educação como ferramenta de mudança social, justificando o maior investimento nesta área de atuação.

Palavras-chave: Responsabilidade Social. Ações sociais. Estudo de caso. Artigos.

\section{ABSTRACT}

This study aims to identify and analyze the social responsibility practices (RS) adopted by Brazilian entities and narrated the events in the studies of the National Association of Graduate Studies and Research in Administration (ANPAD), during the period from 2002 to 2012. The sample utilized in this study was composed by 30 (thirty) articles treating business experiences in RS during the study period. The discoveries showed that: a) a possible change of posture took place, since previously, the corporations directed a good part of their social actions to their collaborators, and at present, they adopt

\footnotetext{
${ }^{1}$ Artigo recebido em 30.04.2013. Revisado pelos pares em 10.07.2013. Aceito para publicação em 15.07.2013. Recomendado para publicação por José Ribamar Marques de Carvalho (Editor Científico). Publicado em 17.07.2013. Organização responsável UACC/UFCG.
} 
strategies for the inclusion of society and the environment in the actions taken for this purpose; $b$ ) there is a search, by the organizations, for more joint partnerships with the government, at the state and municipal levels, since they are looking to act in the regions close to their installations; and c) the focus of managers in education as a tool for social change, justifying larger investments in this area.

Key words: Social Responsibility. Social Actions. Case Study. Articles.

\section{INTRODUÇÃO}

Diante de um crescimento econômico e social acentuado, que remota o período da revolução industrial, que modificou e criou novas técnicas de trabalho, mudou a postura das pessoas e a forma de lidar com a produção; as consequências da má utilização do ambiente e exploração desordenada dos recursos naturais criaram uma nova visão na sociedade que vem encarando com mais seriedade a questão da produção conscientemente correta.

O termo Responsabilidade Social (RS) surgiu num manifesto subscrito por 120 industriais ingleses. O documento tratava da definição da RS, onde a definição dada era de manter um equilíbrio justo entre os vários interesses dos públicos, dos consumidores, dos funcionários e dos acionistas (OLIVEIRA, 2002).

Para Oliveira (2002), o conceito de RS ainda está em fase de definição, apesar de ser adotado há mais de três décadas. Para alguns, ela representa a ideia de responsabilidade ou obrigação legal, apenas uma forma de cumprir lei, enquanto para outros RS significa um comportamento responsável no sentido ético e social. Há ainda aqueles que julgam que o significado está vinculado no contexto em que se encontra. "O conceito de Responsabilidade Social não é fixo, ele varia conforme o desenvolvimento cultural, econômico e político da sociedade no decorrer do tempo" (MACHADO, 2003, p.270).

Cada vez mais as organizações privadas estão se mostrando interessadas em realizar atividades de RS, apesar de que nem sempre, na prática, o discurso se revela. Albuquerque (2009) salienta que uma organização preocupada em implantar uma cultura ética e de RS deve definir princípios claros e simples para que todos os empregados entendam e assimilem. Ele julga, também, que a empresa deve investir em treinamentos para que os funcionários ajam de acordo com os valores e princípios estabelecidos, consolidando-se com ações do dia a dia. Ainda para o autor, as organizações devem estabelecer um código de ética escrito, com o objetivo de mostrar os incentivos e punições estabelecidas.

Neste contexto, Tenório (2006) acrescenta que a responsabilidade social de uma empresa consiste na sua decisão de participar mais diretamente das ações comunitárias na região em que está presente e no esforço de reduzir impactos de possíveis danos ambientais decorrentes do tipo da atividade que exerce. Isso deve acontecer, não por força de regulamentos ou leis, mas por iniciativa própria que as empresas devem agir socialmente. Muitas empresas praticam ações sociais como forma de obrigação, que não podem, assim, serem consideradas sociais, conforme 
comenta Corrêa e Medeiros (2003, p.56) ao afirmar que a obrigação social corresponde àquilo que a empresa faz pelo social que está previsto em lei, desde o pagamento de impostos até a utilização de filtros nas chaminés de fábricas. $O$ Instituto Ethos considera a empresa socialmente responsável quando esta vai além da obrigação de respeitar as leis, pagar impostos e observar as condições adequadas de segurança e saúde para os trabalhadores.

No Brasil, há algum tempo já se vem discutindo o resultado que as organizações vem obtendo em razão da realização de ações de RS, sejam essas organizações públicas ou privadas. As ações desses projetos são diversas e confrontadas em diversas áreas, tais como educação, cultura, saneamento, habitação, esporte, lazer, projeto de educação ambiental e projeto de preservação de prevenção a danos ambientais, etc. Nos estudos bibliométricos sobre a RS encontrados nos eventos da Associação Nacional de Pós-Graduação e Pesquisa em Administração (ANPAD), contudo, verifica-se uma lacuna com relação a quais são as áreas de investimento, quais são os públicos que são priorizados, bem como se as organizações estão fazendo parceria a fim de desenvolver práticas de RS.

É nesse contexto que surge o seguinte problema de pesquisa: quais as práticas de RS adotadas por empresas brasileiras e narradas nos estudos de caso publicados pelos congressos vinculados a ANPAD?

Para tanto, objetiva identificar e analisar as práticas de RS adotadas por empresas brasileiras e narradas nos estudos de caso publicados pelos congressos vinculados a ANPAD.

A escolha dos congressos da ANPAD deu-se em razão desses congressos terem um número relevante de publicações de qualidade voltadas para a temática desse estudo.

\section{REFERENCIAL TEÓRICO}

\subsection{Responsabilidade Social: Conceitos e Origem do Termo}

O interesse em RS por parte das organizações está crescendo à medida que o papel dos negócios na sociedade aumenta. Esse aumento, contudo, está relacionado com a globalização e os avanços tecnológicos que apresentam grandes desafios para as organizações que estão buscando maiores competitividade e produtividade, além da preocupação cada vez maior com a legitimidade de sua atuação na sociedade. Este fato ocorre porque hoje em dia a sociedade está mais consciente, exigente e disposta a participar, de certa forma, desta mudança. Diante das novas perspectivas, um novo modelo econômico surge e dá margem a críticas e opiniões de estudiosos e pesquisadores.

Para os gestores Kringsner e Kapaz da empresa O Boticário, em entrevista para Mendonça (2004) da revista Fae Business, a RS é uma forma de transferir seu foco, servir os interesses dos donos, para aliar esta proposta em servir também aos 
interesses dos diversos grupos que afetam ou são afetados pelas organizações. Segundo Kringsner, o gestor deve acreditar que, independente do tamanho de seu negócio, ou da sua origem, pode trazer ganhos efêmeros e contribuir para um mundo melhor; e que o que acontecerá depois desta predisposição genuína é consequência.

Sendo assim, a RS surge, portanto, com o objetivo de resgatar a função social da empresa, assim como promover o desenvolvimento sustentável. Deixou de ser ainda interessada apenas num retorno para os acionistas e dirigentes e voltou seus olhos para o meio onde está situada. Além de muitas reinvidicações que "nasceram" para solidificar ainda mais a visão da sustentabilidade e derrubar uma visão conservadora e voltada apenas para interesses próprios, foram criados Institutos como o Ethos com o objetivo de promover a Responsabilidade Socialempresarial através de políticas criadas para ajudar as empresas a atuarem em parceria com a comunidade, sobretudo programar práticas voltadas para seu negócio.

Responsabilidade Social Empresarial, segundo o Instituto Ethos, define-se pela relação ética e transparente da empresa com todos os seus stakeholders e pelo estabelecimento de metas empresariais relacionadas com o desenvolvimento sustentável da sociedade através da preservação de recursos ambientais e culturais para as gerações futuras, respeitando a diversidade e promovendo a redução das desigualdades sociais.

Hoje, pode-se dizer que a empresa além de buscar a lucratividade, deve fazêla com respeito e ética aos interesses de todos os envolvidos, àqueles que participam direta ou indiretamente de seu processo produtivo, que são os acionistas, fornecedores, funcionários, meio ambiente, governo, consumidor, etc.

As consequências de uma política de RSE, segundo Grajew (2002), é a criação de uma imagem institucional e da marca, sobretudo uma sólida relação com todos os interessados (stakeholders), ainda uma forma sábia de reter talentos, além de ser flexível e ser dotada de capacidade de adaptação num mercado tão instigante e instável. Garay (2001) salienta que as organizações, ao agirem, adicionam suas competências éticas e políticas através da participação junto ao Estado, a sociedade Civil e grupos de cidadãos. Percebe-se que as organizações compreendem um conjunto de ações voltadas tanto para seus interessados internos, quanto para os externos.

Segundo Melo Neto e Froes (2001), existem três estágios da RSE:

a)Gestão social interna: ações de responsabilidade voltadas para seus funcionários, através de medidas como atividades em prol da saúde, segurança e qualidade do ambiente de trabalho;

b)Gestão social externa: refere-se a atividades voltadas para o meio ambiente (poluição, uso dos recursos naturais, etc.); à sociedade (demissões, comunidade ao redor da empresa) e aos seus consumidores (segurança e qualidade dos produtos)

c) Gestão social cidadã: relacionada a questões de bem-estar da sociedade através de benfeitorias realizadas na comunidade, como o voluntariado e 
implementação de projetos sociais. Melo Neto e Froes (1999) ainda destacam que uma empresa cidadã é reconhecida pela excelência de sua atuação social, ganha a confiança, o respeito e a admiração dos consumidores.

A Responsabilidade Social chegou para interligar as organizações aos demais interessados neste processo evolutivo, tornando-os capazes de reconhecer seus impactos ambientais e sociais, bem como, reconstruir uma relação ética e duradoura com todos os interessados. Ursini e Bruno (2003), da Fundação de Apoio a Tecnologia acreditam, no que diz respeito à educação social, que as empresas podem, por exemplo, provocar momentos de formação sobre o tema da Responsabilidade Sociale o desenvolvimento sustentável, convidando seus públicos de interesse a refletirem sobre sua atuação em relação a essas questões.

Seguindo esse pensamento, Capra (2005, p.33) diz que "é através da educação que o processo da Responsabilidade Social será compreendido por todos; e a consequência será a motivação em prol da mudança". Esse autor ainda lembra que:

\footnotetext{
À medida que nosso século se desdobra, a sobrevivência da Humanidade dependerá de nossa alfabetização ecológica: nossa capacidade de compreender os princípios básicos da ecologia e viver de acordo com eles. Este é um empreendimento que transcende todas as diferenças de raça, cultura ou classe social. A terra é nosso lar comum, e criar um mundo sustentável para nossas crianças e para as futuras gerações é uma tarefa para todos nós (CAPRA, 2005, p.33).
}

É através da educação que será possível uma maior conscientização em massa dos problemas norteadores de uma sociedade diretamente envolvida nos processos e impactos decorrentes das atividades empresariais. Leonardo Boff é um dos estudiosos na área de RS, o qual tem como preocupação mostrar a importância dessa ferramenta para o desenvolvimento da entidade. Para Boff (2005), estamos diante de um cenário crítico na história da terra, num momento em que todos devem escolher o seu futuro; ou formar uma aliança global para cuidar da terra e uns dos outros, ou arriscar a nossa destruição e da diversidade da vida.

Mesmo tendo muitas empresas focadas em busca de um desenvolvimento sustentável, trabalhando para minimizar uma situação emergente e consequente de práticas não pensadas inicialmente, ainda serão necessários grandes esforços para chegar ao seu ponto ótimo. Diante disso, cabe destacar uma abordagem de Kringsner, presidente da empresa $\mathrm{O}$ Boticário que aborda o grande crescimento acentuando da população e sua maior complexidade. Para ele, estes fatos estão dificultando as ações do governo, de forma geral, em todo o mundo, pois já não conseguem atender as demandas econômicas, sociais, políticas e ambientais, cabendo às empresas dividir esta responsabilidade, pois hoje é considerada uma força alavancadora na sociedade (MENDONÇA, 2004). 
Enquanto muitos acreditam que a mudança e a obrigação estão nas mãos do governo, outros, como Kringsner, atrelam à empresa. Ele acredita que é importante a parceria da empresa com o Estado, pois se o governo faz sua parte e se aliar às iniciativas privadas, o resultado será uma combinação muito positiva de visões diferentes e complementares que só beneficia a sociedade porque para ele, "juntos, somos sempre mais fortes". Ainda há outros que dizem que a RS é parte empresarial; de governo e, ainda, da própria sociedade concomitantemente (MENDONÇA, 2004).

É importante ressaltar, porém, que ainda há outros pesquisadores na área de RSE que a relacionam como uma forma de marketing que apenas mascara uma ideologia que não é cumprida. Para eles é apenas uma forma obrigatória de cumprir leis e regulamentos impostos; de dar emprego, ou assistência a seus trabalhadores. Não que isso não pode ser considerado um ato de RS, mas é formada por uma série de atividades voltadas em prol de uma sociedade mais justa, saudável e duradoura. Melo Neto e Froes (1999) acreditam que apoiar o desenvolvimento da comunidade e preservar o meio ambiente não são suficientes para atribuir a uma empresa a condição de socialmente responsável.

\subsection{Reponsabilidade Social no Brasil: Nascedouro e Organismos Incentivadores}

Apesar das inúmeras discussões e exigências, no Brasil, o conceito de RS ainda é confundido com os investimentos que as empresas fazem. Para Albuquerque (2009), o tema passou a ser discutido no Brasil no início da década de 80, como resultado aos esforços do sociólogo Herbert de Souza, O Betinho, que trouxe a campanha contra a fome e a miséria. No início da década de 80 , ele fundou o Instituto Brasileiro de Análises Sociais e Econômicas (IBASE) com o objetivo de dedicar à democratização da informação sobre as realidades econômicas, políticas e sociais do Brasil, juntamente com outros profissionais interessados nessa temática.

Segundo Rizzi (2002), a tendência é que cada vez mais as empresas fiquem dependentes de todos os seus interessados, tais como seus funcionários, fornecedores, acionistas, comunidade e governo, que estão cada vez mais ficando exigentes e buscando um bom tratamento. A sociedade atual está exigindo maiores ações das empresas. Oliveira (2002) acrescenta que cresce a conscientização das pessoas mesmo a empresa gerando emprego, benefícios à sociedade, criando produtos, etc.

O cenário atual demonstra que as organizações não estão sendo apenas questionadas pelo que fazem, mas especialmente pelo que deixam de fazer. A falta de participação, o descaso com os problemas da comunidade, a pouca qualidade dos produtos e serviços, tudo é motivo para perguntas, cobranças e retaliações (OLIVEIRA, 2002, p.35). 
A temática 'ações sociais' vem cendo um dos assuntos cada vez mais emergente atualmente. As ações das empresas estão tendo a cobertura da mídia que de certa forma promove o marketing social da empresa.

No Brasil, a discussão sobre o tema está associada à mudança de valores que o país está passando, de uma sociedade industrial, onde a RS se destaca como uma ideia conotativa econômica, para uma sociedade pós-industrial, onde o tema é valorizado em aspectos relacionados à melhoria da qualidade de vida.

No Brasil, o termo Responsabilidade Social foi ganhando força com a ajuda de muitas organizações empenhadas na efetivação dessas práticas, das quais, podem-se destacar três entidades apresentadas no quadro 1:

\begin{tabular}{|c|c|}
\hline ENTIDADE & COMO INCENTIVA \\
\hline $\begin{array}{l}\text { Grupo de } \\
\text { Institutos, } \\
\text { Fundações e } \\
\text { Empresas (GIFE) }\end{array}$ & $\begin{array}{l}\text { Congrega instituições de origem privada que, de forma voluntária e sistemática, } \\
\text { investem recursos privados- humanos, técnicos ou financeiros, em que projetos } \\
\text { sociais com a missão de aperfeiçoar e difundir os conceitos e práticas do uso de } \\
\text { recursos privados para o desenvolvimento do bem comum (CORREA; } \\
\text { MEDEIROS, 2003). }\end{array}$ \\
\hline $\begin{array}{l}\text { Fundação } \\
\text { Abrinq pelos } \\
\text { Direitos da } \\
\text { Criança }\end{array}$ & $\begin{array}{l}\text { A Fundação Abrinq estimula e pressiona a implementação de ações públicas, } \\
\text { sobretudo fortalece as organizações governamentais e não-governamentais para a } \\
\text { prestação de serviços sociais na defesa de direitos das crianças e adolescentes } \\
\text { (MELO NETO; FROES, 1999). }\end{array}$ \\
\hline $\begin{array}{l}\text { Pensamento } \\
\text { Nacional das } \\
\text { Bases } \\
\text { Empresarias } \\
\text { (PNBE) }\end{array}$ & $\begin{array}{l}\text { O PNBE vem desenvolvendo projetos sociais nas empresas privadas com outras } \\
\text { entidades; ou com empresas privadas ou instituições públicas, tanto na área de } \\
\text { educação quanto ambiental, social de centro de convivências e de combate à fome } \\
\text { (CORREAA; MEDEIROS, 2003). }\end{array}$ \\
\hline
\end{tabular}

Quadro 1 - Entidades que incentivam práticas de Responsabilidade Socialno Brasil

Fonte: Elaboração própria dos autores com base em Melo Neto e Froes (1999), Corrêa e Medeiros (2003), Karkotli (2006).

\subsection{Pesquisas sobre Responsabilidade Social no Brasil}

Esta seção do artigo apresenta de forma cronológica um grupo de estudos sobre RS publicados no Brasil no período de 2002 a 2010. O Primeiro estudo foi publicado no Encontro da Associação Nancional de Pós-graduação em Administração (ENANPAD) na edição de 2002 pelos pesquisadores Lage e Machado (2002), mostra uma experiência de atuação empresarial responsável, através de um estudo de caso na Companhia Vale do Rio Doce (CVRD) em alguns projetos possíveis de serem implantados em comunidades carentes. A pesquisa mostrou que as ações da Companhia estavam contribuindo para a ascensão social da comunidade e que a empresa tinha o interesse de garantir um futuro satisfatório para toda a comunidade, haja vista que suas ações de explorações eram irreparáveis.

Coelho et al. (2005) buscaram analisar práticas de RS no ambiente interno de duas grandes empresas sediadas em Minas Gerais que eram signatárias da Agenda 
Global Compact das Nações Unidas com o objetivo de avaliar tais práticas, no tocante à relação aos avanços e desafios de manter uma postura ética e duradoura com seus colaboradores. As informações foram colhidas através de entrevistas com duzentos e noventa e dois (292) funcionários de Janeiro a Abril de 2004 que demonstraram que os funcionários sentiam-se satisfeitos com as ações das empresas e que, segundo eles, a empresa investia em segurança e saúde de todos, sobretudo no combate ao trabalho infantil.

Moratelli e Souza (2006) elaboraram um projeto de pesquisa em quarenta (40) hotéis filiados à Associação Brasileira da Indústria de Hotéis (ABIH) entre agosto e outubro de 2005 baseados num estudo de caso onde tratou da percepção dos gestores sobre as práticas de RS nas empresas hoteleiras de Santa Catarina. Os resultados da pesquisa demonstraram que no estado de Santa Catarina, dentre os hotéis pesquisados, cerca de dezessete (17), possuíam políticas de ações sociais responsáveis, segundo a percepção dos gestores da área que sempre se preocupavam em seguir as leis para que não estivessem vulneráveis a receber multas. Isso fazia com que esses hotéis trabalhassem de acordo com normas legais. Pode-se perceber com essas atitudes que a maioria voltava suas ações a fim de atender os interesses dos stakeholder governo.

Oliveira e Silva (2006) concentraram suas pesquisas com o objetivo de analisar as estratégias de RS que estão sendo aplicadas pelas organizações e como isso está sendo feito pelas empresas atuais. Utilizaram, para tanto, um estudo de caso sobre os duzentos e trinta e um (231) casos concretos do Instituto Ethos que demonstrou que muitas dessas empresas não obtêm total percepção de como utilizar suas estratégias, haja vista que esse termo ainda é muito confundido com ação social e filantrópica. Sendo a primeira adotada por cerca de 44,63\% dos casos e $15 \%$ em ações filantrópicas.

Gonçalves, Grillo e Borger (2007) elaboraram um estudo com o objetivo de evidenciar a forma e a abrangência de evidenciação de ações de RS por bancos privados, sobretudo discutir as evidenciações e informações expostas nos sites dessas organizações e o esforço em aderir a essas ações. Foi utilizado um estudo de caso em três bancos: o Bradesco, o Itaú e o Unibanco para atender ao objetivo da pesquisa. A pesquisa mostrou que os bancos atuam de forma compatível com as exigências em alguns aspectos, enquanto em outros não são totalmente transparentes quando se trata de informações, tais como reclamações, causas judiciais trabalhistas, entre outras. Também os bancos erram quando transferem suas informações, porque não fazem de forma sistêmica e estruturada, quando se tem necessidade de buscar informações em seus relatórios ou balanços, os dados ficam desestruturados gerando confusões em seu entendimento.

Figueiredo e Moretti (2007), por sua vez, procuraram demonstrar que existe uma reprodução no discurso de muitos autores em relação à RS, e que muitos deles optam pela pesquisa operacional do que nos fundamentos da RS, tudo isso para que sejam evitadas novas discussões. Foram avaliados cerca de vinte (20) artigos dentre 
cento e noventa e oito (198) produzidos entre 2003 e 2006, onde foi comprovado que existem poucas discussões e elaborações de uma pesquisa de RS atual, onde a maioria dos autores concentra-se em pesquisas já elaboradas e modelos já estabelecidos.

Cruz et al. (2010) elaboraram uma pesquisa através da interação com as comunidades beneficiadas com projetos sociais, com o intuito de avaliar e descrever uma experiência de extensão universitária implantada há 20 anos e que já capacitou mais de oitocentos (800) moradores ligados a arquidiocese do Rio de Janeiro. Com a pesquisa-ação identificou-se que os benefícios são gerados para todos os envolvidos nos projetos, tanto para a comunidade e instituição, quanto para os pesquisadores que adquiriram experiência docente, publicações da experiência e elaboração de políticas públicas.

Borger et al. (2010) fizeram um estudo com o objetivo de discutir a importância da responsabilidade sócio ambiental na integração logística na empresa Bunge S/A a partir de informações obtidas em relatórios de sustentabilidade de 2007 e 2008, entrevistas realizadas com executivos e levantamentos de documentos já elaborados. A Bunge demonstrou nesse estudo que adota uma gestão socioambiental desde a homologação de seus fornecedores, até na avaliação de seus serviços e divulgação de ocorrências na execução de transporte ou armazenagem de produtos.

Nakayama e Teixeira (2010) elaboraram um estudo de caso na empresa O Boticário com o objetivo de analisar as ações de RS da empresa com relação ao stakeholder fornecedor e suas ações implantadas, que foram baseadas nos indicadores Ethos de Responsabilidade Social e na visão de seus sócios e dirigentes, conseguidos através de entrevistas e análise de documentos que demonstraram que os indicadores Ethos são encarados com muito rigor pela empresa que está sempre preocupada em conciliar sua força institucional com ações que envolvam seus funcionários que, por sua vez, tornam-se satisfeitos através da imagem da empresa e têm suas revoltas amortizadas.

Backes et al. (2010), com o intuito de retratar a gestão da RS em empresas beneficiadoras de tabaco na região sul do Brasil, elaboraram um estudo de pesquisa com cinco indústrias beneficiadoras de tabaco através de questionários que demonstraram que as empresas sentem-se pressionadas pelo mercado que exige uma atuação conjunta do setor, justamente porque o segmento fumageiro é de total importância para a economia onde essas empresas estão instaladas.

Leal e Rego (2010) realizaram um estudo com o objetivo de analisar a RSE sendo avaliadas em três dimensões: econômica, legal e ética, para as quais utilizaram questionários e testes com duzentos e cinquenta e dois (252) membros organizacionais dos diversos setores da economia, onde foi possível concluir na visão dos entrevistados que a responsabilidade deve ser reconsiderada e reformulada, haja vista que, dependendo de quem analisa, são percebidas de formas diferentes, tanto pelos funcionários, sociedade, quanto para o ambiente. 
Dias e Medeiros (2010) fizeram um estudo em oito (8) corporações do setor elétrico dentre quinhentos e cinquenta e quatro (554) empresas instaladas na Bolsa e oitenta e oito (88) no site com ações de RS corporativa com o objetivo de entender seu surgimento e sua disseminação entre as corporações à luz dos conceitos já estabelecidos. Pôde-se perceber com a pesquisa que as empresas inserem as ações de RS em seus planejamentos e criam indicadores para mensurar seus resultados e análises. Isso permite à empresa acompanhar todas as etapas de uma implementação de ações sociais.

\section{PROCEDIMENTOS METODOLÓGICOS}

Esta seção do artigo apresenta os procedimentos metodológicos utilizados durante a realização da pesquisa, com destaque ao método, as tipologias, os procedimentos de coleta e de análise de dados. O método utilizado na pesquisa foi o método indutivo, o qual parte de dados particulares, no caso deste estudo, das experiências individuais das empresas com relação às práticas de RS, e chega-se a uma possível verdade geral do fato, ou seja, como as empresas brasileiras estão desenvolvendo práticas de RS através das narrativas encontradas nos artigos pulicados nos eventos da ANPAD.

Toda pesquisa para alcançar seus objetivos precisa ter seus elementos de estudos definidos; sendo assim, é de total importância definir o universo e a mostra utilizada.. Denomina-se universo porque é constituído por todos os elementos de uma classe, ou toda uma população (RICHARDSON, 2007). O universo deste estudo foram os cento e sessenta e seis (166) artigos sobre RS, publicados nos eventos da ANPAD entre 2002 e 2012.

Já a amostra é caracterizada por qualquer subconjunto do conjunto universal ou da população, por meio do qual se estabelece ou se estima as características desse universo ou população. Segundo Andrade e Martins (2003), tratam-se da escolha de determinada quantidade dos elementos de uma classe para o objeto de estudo. No caso, desta pesquisa a amostra foi composta por trinta e três (33) artigos publicados nos eventos da ANPAD que apresentaram estudo de caso único descrevendo experiências de com práticas de RS.

Tipologia da pesquisa pode ser classificada por inúmeras formas e critérios

que vão variar segundo diferentes enfoques. Neste trabalho foi utilizado a classificação de Beuren et al (2008), classificando o mesmo:

\section{a) Quanto aos objetivos em exploratório e descritivo.}

Exploratório porque o tema não é amplamente discutido na literatura e não há muitos trabalhos de pesquisa que tratam sobre experiências de projetos já elaborados sobre Responsabilidade Socialempresarial. Por esse motivo, esse estudo tem como objetivo demonstrar os estudos já realizados por pesquisadores sobre RSE no Brasil e 
no mundo. Já é descritivo em razão de ter como objetivo descrever os resultados da pesquisa sem a interferência dos pesquisadores nas variáveis estudadas (MEDEIROS, 2007).

b) Quanto aos procedimentos, esta pesquisa é classificada em bibliográfica e documental.

O início da pesquisa foi marcado por um estudo baseado em análise de artigos de estudos sobre RSE já realizados por profissionais interessados no tema no Brasil e no mundo. Foram consultados revistas, livros e artigos relacionados à RSE para dar embasamento aos estudos, e foi feito um levantamento de alguns estudos referente ao tema de RSE. Esse estudo é documental porque teve como fonte de dados primários, os artigos publicados nos anais da ANPAD, com estudos de caso únicos, que tratam sobre experiências de práticas de RS.

c) Quanto à abordagem a pesquisa é classificada como mista, ou seja, qualiquanti.

O carácter qualitativo é justificado em razão do próprio objetivo central do estudo, que é investigar características das práticas de RSE em empresas brasilieras. Já o caráter quantitativo foi dado na forma que os dados foram tratados e apresentados na seção votada para os resultados do estudo documental, com o uso de dados numéricos, percentuais e de médias. Segundo Malhotra (2001, p. 155) “a pesquisa quantitativa procura quantificar os dados e aplicar alguma forma de análise estatística".

Para a coleta de dados primários, foi elaborado um formulário, cujo objetivo inicial foi padronizar as informações coletadas. Esse instrumento de coleta de dados foi elaborado com base nos objetivos apresentados na seção introdutória deste trabalho, portanto, através deste buscou-se saber se:

INFORMAÇÕES LEVANTADAS APÓS ANÁLISE TEXTUAL DOS ESTUDOS DE CASO ÚNICOS

Existência de um setor específico responsável pelo desenvolvimento das ações de RS nas empresas; Existência de parceria entre a empresa e o meio externos para o desenvolvimento das ações de RS. Qual público é assistido através das ações de RS desenvolvido pela organização; Do público assistido pelas ações de RS, quais foram priorizados;

As áreas de atenção para quais são desenvolvidas as as ações de RS voltadas para os seus públicos.

\section{Quadro 2 - Descrição do formulário de coleta de dados}

Fonte: Elaboração própria dos autores.

Após o levantamento dos dados, através do formulário, foi feita uma análise descritiva de todas as informações colhidas. Porém, faz-se importante ressaltar que, a existência de um fator limitante encontrado nesta pesquisa, a pequena quantidade de estudos de casos únicos abordando experiências com adoção de práticas de RS; 
embora esse fato contribua para a relevância da realização do presente estudo, pois a temática central ainda é pouco explorada.

A ANPAD promove anualmente vários eventos de diversos segmentos que contribuem para interligar professores, pesquisadores e estudantes em diversos assuntos. Os eventos relacionados são o Encontro da Associação Nacional de PósGraduação e Pesquisa em Administração (EnANPAD), Encontro de Estudos Organizacionais (EnEo), Encontro de Estudos em Estratégias (3ES), Encontro de Administração Pública e Governança (EnAPG) e Encontro de Marketing da ANPAD (EMA). Esses eventos são desmembrados em sessões que formam uma divisão acadêmica dos diversos temas, ou seja, eles são agrupados de modo que seja facilitado o intercâmbio com seus associados. Os agrupamentos permitem incitar as mais diversas discussões acerca dos temas pertinentes ao campo das ciências administrativas, contábeis e afins.

\section{APRESENTAÇÃO E DISCUSSÃO DOS RECULTADOS}

Esta seção do trabalho apresenta os dados obtidos através da pesquisa documental, tendo como fonte os artigos publicados nos anais do eventos científicos da ANPAD durante o período de 2002 a 2012, bem como a interpretação desses dados com base no objetivos apresentados na introduçao deste trabalho.

A tabela 1 apresenta os eventos científicos da ANPAD realizados durante os anos de 2002 a 2012. Os artigos selecionados foram publicados nos eventos mencionados e todos tratam de experiências com práticas de RSE levantadas a partir de pesquisas exploratórias em empresas de vários segmentos. Nos artigos foram detectados inúmeros casos de ações de Responsabilidade Sociale vários retornos para quem as pratica. Com base na tabela 1 , nota-se que o evento científico que mais divulgou trabalhos, com estudo de caso único, tratando sobre experiências de RS foi o ENANPAD, com 78,8\% dos artigos que servirão de fonte de dados documental para a realização do presente estudo.

Tabela 1 - Artigos sobre RS com a existência de estudos de casos publicados nos congressos da ANPAD

\begin{tabular}{l|c|c|c|c|c|c}
\hline Evento & EnANPAD & EnEO & 3ES & EnAPG & EMA & Total \\
\hline Quantidade de artigos & 26 & 3 & 2 & 1 & 1 & 33 \\
\hline Percentual & 78,8 & 9,1 & 6,1 & 3,0 & 3,0 & 100,0 \\
\hline
\end{tabular}

A tabela 2 representa o número de trabalhos apresentados conforme o período estudado nos cinco eventos da ANPAD nos últimos 10 anos. Os dados indicam um crescimento quase linear dos estudos voltados para o tema Responsabilidade Social até o ano de 2006 quando iniciou um ligeiro decréscimo até o final do período estudado. Os anos de 2005 e 2007 são os anos de 'outliers', que interessantemente são arredores do ano de maior movimento onde $18,2 \%$ dos artigos foram publicados. 
Tabela 2 - Amostra dos artigos sobre RS nos congressos da ANPAD por ano

\begin{tabular}{l|c|c|c|c|c|c|c|c|c|c|c|c}
\hline Ano & 2002 & 2003 & 2004 & 2005 & 2006 & 2007 & 2008 & 2009 & 2010 & 2011 & 2012 & Total \\
\hline Quantidade de artigos & 1 & 3 & 4 & 2 & 6 & 3 & 4 & 4 & 3 & 1 & 2 & 33 \\
\hline$\%$ & 3 & 9,1 & 12,1 & 6,1 & 18,2 & 9,1 & 12,1 & 12,1 & 9,1 & 3 & 6,1 & 100 \\
\hline \%Acumulado & 3 & 12,1 & 24,2 & 30,3 & 48,5 & 57,6 & 69,7 & 81,8 & 90,9 & 93,9 & 100 & \\
\hline
\end{tabular}

Fonte: Elaboração própria dos autores.

A tabela 3 representa os públicos assistidos pelas empresas estudados nos artigos científicos, as correspondentes percentagens não somando a 100 devido ao fato que o programa de RS de uma empresa pode atender a mais de um público. Pode se observar que a as empresas que adota ações e programas de RS dá atenção maior ao público sociedade, que representa $97 \%$ de suas ações, seguido por o meio ambiente com $81,8 \%$, e, finalmente, o grupo de funcionários representando apenas $51,5 \%$. Os dados remetem a ideia de que os stakeholders sociedade e meio ambiente estão influenciando significativamente nas ações atuais das empresas, mostrando que o pensamento inicial, voltado apenas para os interesses internos, está sendo substituído pelo externo.

Tabela 3 - Público assistido pelas empresas estudadas com programas de RSE

\begin{tabular}{l|c|c|c|c}
\hline Público & Colaboradores & Sociedade & $\begin{array}{c}\text { Meio } \\
\text { Ambiente }\end{array}$ & Total \\
\hline Ocorrência & 17 & 23 & 27 & 33 \\
\hline Percentual sobre o TEC $(1)$ & 51,5 & 97,0 & 81,8 & 100,0 \\
\hline
\end{tabular}

(1) TEC=Total dos estudos de caso, trinta e três (33) casos.

Fonte: Elaboração própria dos autores.

A tabela 4 desdobra mais as prioridades das empresas ao adotarem ações de RS indicando qual o público atendido nas ações de RS se for único ou múltiplo. Os dados revelam que, quando se trata de apenas um publico único, o atendimento está direcionado mais à sociedade $(33,3 \%)$, seguido por funcionário $(9,1 \%)$ e o meio ambiente ficando em último lugar com 6,1\%. Quando considera um atendimento múltiplo, a amostra revela que $27,3 \%$ consideram sociedade e meio ambiente, $21,2 \%$ consideram todos os componentes e não há referencia alguma para colaboradores e meio ambiente.

Tabela 4 - Prioridades das empresas estudadas com ações de RSE

\begin{tabular}{l|c|c|c|c|c|c|c}
\hline $\begin{array}{c}\text { Público prioritário } \\
\text { nas ações de RS }\end{array}$ & Colaboradores & Sociedade & $\begin{array}{c}\text { Meio } \\
\text { ambiente }\end{array}$ & $\begin{array}{c}\text { Colaboradores e } \\
\text { sociedade }\end{array}$ & $\begin{array}{c}\text { Sociedade e meio } \\
\text { ambiente }\end{array}$ & $\begin{array}{c}\text { Colaboradores, } \\
\text { sociedade e meio } \\
\text { ambiente }\end{array}$ & Total \\
\hline Ocorrência & 3 & 11 & 2 & 1 & 9 & 7 & 33 \\
\hline$\%$ s/ TEC $(1)$ & 9,1 & 33,3 & 6,1 & 3,0 & 27,3 & 21,2 & 100,0 \\
\hline
\end{tabular}

Fonte: Elaboração própria dos autores. 
Em resumo, os dados expressos na tabela 4 mostram que as ações de RS se mantêm e dão prioridade aos interessados externos. Significa dizer que os movimentos sociais, a comunidade, as exigências do mercado, etc. estão forçando as empresas a adotarem ações voltadas para esses interessados públicos e menos ênfase está direcionada para os seus próprios funcionários, ou eles não consideram as ações direcionadas aos funcionários como programas de RS.

O termo Responsabilidade Social remete a ideia de ações conjuntas e permanentes, sendo assim, é necessário haver uma associação de ações, ou seja, devese existir uma parceria entre os entes, sejam eles públicos ou privados, para que os problemas comuns sejam atacados e resolvidos conjuntamente. Nesse sentido, o estudo identificou quais os parceiros que se associam às empresas para implantar ações e práticas de RS. A Tabela 5 representa o nível de parceria que as empresas têm com o governo municipal, estadual e federal. Os dados revelam que as empresas que atuam com programas de RS buscam parcerias com todos os níveis de governo, os de nível municipal e estadual sendo mais mencionados. Os dados sugerem, portanto, que muitas empresas buscam atuar localmente e nas regiões próximas as suas instalações.

Tabela 5 - Prioridade das empresas em relação ao governo

\begin{tabular}{l|c|c|c|c}
\hline $\begin{array}{l}\text { Parcerias com o } \\
\text { governo }\end{array}$ & Municipal & Estadual & Federal & Total \\
\hline Ocorrência & 30 & 30 & 26 & 33 \\
\hline$\%$ s/ TEC (1) & 90,9 & 90,9 & 78,8 & 100,0 \\
\hline
\end{tabular}

Fonte: Elaboração própria dos autores.

A tabela 6 faz o levantamento dos setores que as ações sociais das empresas estudadas são planejadas e monitoradas, dentre os quais foram identificados o setor de Recursos Humanos (RH) que geralmente são acionados quando as ações são direcionadas para os colaboradores; o marketing que tem papel importante na disseminação dessas ações; as fundações próprias, que cuidam desde o planejamento até o gerenciamento dos resultados e os setores específicos, que não foram divulgados pelas empresas, mas que fazem parte das estratégias empresariais das empresas quando querem implantar programas de RS.

Apesar da identificação desses setores, o setor de marketing vem se destacando em relação aos demais, representando $81,8 \%$ dos casos nas empresas estudadas com programas de RS. O resultado está relacionado com o interesse atual das empresas em disseminar suas práticas e torná-las mais transparentes, a fim de a sociedade saber reconhecer a função social da empresa, aumentando, assim, a visibilidade da própria organização.

Tabela 6 - Setores que cuidam da RS nas empresas estudadas

\begin{tabular}{l|c|c|c|c|c|c}
\hline $\begin{array}{l}\text { Quem cuida das } \\
\text { ações de RS ? }\end{array}$ & $\begin{array}{c}\text { Recursos } \\
\text { Humanos }\end{array}$ & Marketing & $\begin{array}{c}\text { Fundação } \\
\text { própria }\end{array}$ & $\begin{array}{c}\text { Setor } \\
\text { específico }\end{array}$ & $\begin{array}{c}\text { Sociedade e } \\
\text { meio }\end{array}$ & Total \\
\hline
\end{tabular}




\begin{tabular}{l|c|c|c|c|c|c}
\hline & & & & & ambiente & \\
\hline Ocorrência & 14 & 27 & 20 & 7 & 9 & 33 \\
\hline$\%$ s/ TEC (1) & 42,4 & 81,8 & 60,6 & 21,2 & 27,3 & 100,0 \\
\hline
\end{tabular}

Fonte: Elaboração própria dos autores .

As áreas de atenção dos programas de RS são apresentadas na tabela 7. A maioria das organizações, $(87,9 \%)$, busca atuar através da educação ambiental, de modo que a sociedade, uma vez educada, saberá reconhecer essas atitudes responsáveis e, de certa forma, contribuirá com as ações da organização. Outras duas áreas de grande importância e interesse das empresas são as de educação geral $(69,7 \%)$ e da de estímulo ao voluntariado (66,7\%). As áreas de cultura, saúde e benefícios diversos são alguns dos interesses internos quando se trata de ações voltadas para o stakeholder colaborador.

Tabela 7 - Áreas de atenção das empresas que promovem ações sociais

\begin{tabular}{|c|c|c|c|c|c|c|c|c|c|c|c|c|}
\hline $\begin{array}{c}\text { Áreas de } \\
\text { atenção }\end{array}$ & 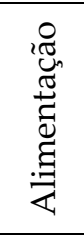 & 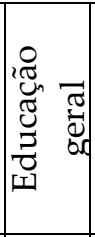 & 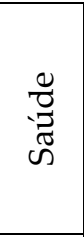 & 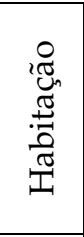 & 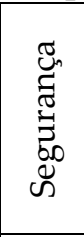 & 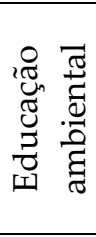 & 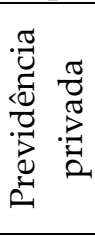 & 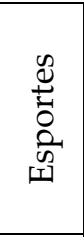 & 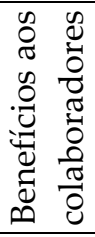 & 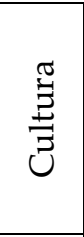 & 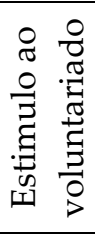 & 胥 \\
\hline Ocorrência & 5 & 23 & 15 & 8 & 8 & 29 & 15 & 9 & 19 & 17 & 22 & 33 \\
\hline$\%$ s/ TEC (1) & 15,2 & 69,7 & 45,5 & 24,2 & 24,2 & 87,9 & 45,5 & 27,3 & 57,6 & 51,5 & 66.7 & 100,0 \\
\hline
\end{tabular}

Com base na tabela 7 verifica-se que as áreas de atuação das práticas de ações sociais de RS menos citadas nos estudos de casos foram alimentação, habitação e segurança. A justificativa para o pouco foco das ações empresariasi nas duas últimas áreas, talvez se deva ao fato dos gestores das organizações acharem que segurança e habitação (moradia) sejam funções sociais a serem desenvolvidas pelo estado.

\section{CONSIDERAÇÕES FINAIS}

Esta seção do trabalho expõe as conclusões obtidas após a realização dos estudos secundários e primários que nortearam esta pesquisa, relacionados com os objetivos pretendidos e apresentados na primeira parte deste artigo. Após investigação dos eventos da ANPAD, verificou-se o ENANPAD, como o evento científico com maior quantidade de divulgação de trabalhos. Estes, por sua vez, contendo estudo de caso único e abordando as experiências de RS, ou seja, 78,8\% da amostra estudada. Além disso, os dados indicam um crescimento, quase linear, das pesquisas voltadas para o tema "Responsabilidade Social" no ano de 2006, em 
contrapartida ao período compreendido entre o ano subsequente até 2012 , onde foi evidenciado um ligeiro decréscimo.

Buscou-se também verificar qual o público priorizado pelas entidades, com relação à adoção de ações e programas de Responsabilidade Social, onde a descoberto que o foco é para a sociedade. Este achado demonstra uma possível mudança de postura, pois antes, as empresas direcionavam mais ações sociais e recursos para o seu público interno, ou seja, para os seus colaboradores, e atualmente, procuram estratégias de ação para incluir nesse processo os colaboradores, a sociedade e o meio ambiente.

O sentido maior do termo "Responsabilidade Social" remete à ideia de ações conjuntas e permanentes, sendo assim, verificou-se ao longo do estudo: as corporações brasileiras que atuam com programas de RS, buscam parcerias com todos os níveis de governo, sendo os de nível municipal e estadual, como os mais mencionados, e sugerindo assim, a grande quantidade de empresas atuando localmente e nas regiões próximas às suas instalações.

Além de descobrir quais os públicos assistidos com os programas de RS, este trabalho investigou sobre quais eram as áreas de foco destes programas. Os resultados demonstraram: a maioria das organizações, ou seja, 87,9\% atuam através da educação ambiental. Outras duas campos de grande importância e interesse das entidades são as de: educação geral $(69,7 \%)$ e de estímulo ao voluntariado $(66,7 \%)$. Este resultado reflete a preocupação dos gestores dessas organizações para com a educação como ferramenta de mudança social.

Todavia, as áreas de menor atenção de acordo com as organizações pesquisadas foram: alimentação, segurança e moradia. A justificativa com relação aos dois últimos campos, talvez se deva ao fato dos gestores das organizações analisarem a segurança e a habitação (moradia) como funções sociais a serem desenvolvidas pelo estado.

Por fim, esse estudo trouxe informações características das práticas de RS desenvolvidas por empresas brasileiras, portanto, espera-se contribuição do mesmo para o desenvolvimento de pesquisas futuras nesta área. Fica a sugestão para estudos futuros: realizar pesquisa de levantamento para verificação das constatações encontradas, apresentadas na seção voltada à apresentação e discussões dos resultados, com um número maior de organizações.

\section{REFERÊNCIAS}

ALBUQUERQUE, José de Lima. Gestão Ambiental e Responsabilidade Social: conceitos, ferramentas e aplicações. São Paulo: Atlas, 2009.

ANDRADE, Maria Margarida de; MARTINS, João Alcino de Andrade. Introdução à metodologia do trabalho científico. 6 ed. São Paulo: Atlas, 2003. 
ANAIS DOS EVENTOS DA ANPAD. Disponível em: http://www.anpad.org.br. Acesso em janeiro de 2013.

BACKES, Betina Ines; MARINHO, Sidney Vieira; SELIG, Paulo Mauricio. Práticas de Gestão de Responsabilidade Social: um estudo em indústrias beneficiadoras de tabaco da região sul do Brasil. In: XXXIV ENCONTRO DA ASSOCIAÇÃO NACIONAL DE PÓS-GRADUAÇÃO E PESQUISA EM ADMINISTRAÇÃO, 34, 2010, Rio de Janeiro. Anais... Rio de Janeiro: ANPAD, 2010.

BEUREN, Ilse Maria; RAUPP, Fabiano Maury; SOUSA, Marco Aurélio Batista de; COLAUTO, Romualdo Douglas; PORTON, Rosimere Alves de Bona. Como elaborar trabalhos monográficos em Contabilidade. 4 ed. São Paulo: Atlas, 2008.

BOFF, Leonardo. Ética da vida. Rio de Janeiro: Sextante, 2005.

BORGER, Fernanda Gabriela; MACHADO, Tania Regina de Oliveira; ROBLES, Leo Tadeu. A Responsabilidade Socioambiental como componente da logística integrada: o caso da exportação do complexo de soja pela Bunge Alimentos S/A. In: XXXIV ENCONTRO DA ASSOCIAÇÃO NACIONAL DE PÓS-GRADUAÇÃO E PESQUISA EM ADMINISTRAÇÃO, 34, 2010, Rio de Janeiro. Anais... Rio de Janeiro: ANPAD, 2010.

CAPRA, Fritjof. O ponto de mutação: a ciência, a sociedade e a cultura emergente. 25 ed. São Paulo: Cultrix, 2005.

COELHO, Helena Maria Queiroz; NETO, Antônio Carvalho; PENA, Roberto Patrus Mundim; TEODÓSIO, Armindo dos Santos de Souza. Discurso e Prática da Responsabilidade Social: um estudo sobre a gestão do público interno em empresas signatárias do Global Compact. In: XXIX ENCONTRO DA ASSOCIAÇÃO NACIONAL DE PÓS-GRADUAÇÃO E PESQUISA EM ADMINISTRAÇÃO, 29, 2005, Brasília. Anais... Brasília: ANPAD, 2005.

CORRÊA, Filipe Toscano de Brito Simões; MEDEIROS, João Ricardo Costa. Responsabilidade social corporativa para quem?. In: INSTITUTO ETHOS: Prêmio Ethos Valor. Vários autores. Responsabilidade social das empresas: a contribuição das universidades. v.2. São Paulo: Editora Fundação Petrópolis, 2003. p.151-199.

CRUZ, Breno de Paula Andrade; MALAFAIA, Fernando César Benevenuto; MELO, William dos Santos; TENÓRIO, Fernando Guilherme. Extensão Universitária e Responsabilidade Social: 20 anos de experiência de uma instituição de ensino superior. In: XXXIV ENCONTRO DA ASSOCIAÇÃO NACIONAL DE PÓSGRADUAÇÃO E PESQUISA EM ADMINISTRAÇÃO, 34, 2010, Rio de Janeiro. Anais... Rio de Janeiro: ANPAD, 2010. 
DIAS, Osório Carvalho; MEDEIROS, Janann Joslin. Racionalidades Subjacentes às Ações de Responsabilidade Social Corporativa em Empresas do Setor Elétrico Brasileiro. In: XXXIV ENCONTRO DA ASSOCIAÇÃO NACIONAL DE PÓSGRADUAÇÃO E PESQUISA EM ADMINISTRAÇÃO, 34, 2010, Rio de Janeiro. Anais... Rio de Janeiro: ANPAD, 2010.

FIGUEIREDO, Júlio César Bastos de; MORETTI, Sérgio Luiz do Amaral. Análise Bibliométrica da Produção sobre Responsabilidade Social das Empresas no ENANPAD: evidências de um discurso monológico. In: XXXI ENCONTRO DA ASSOCIAÇÃO NACIONAL DE PÓS-GRADUAÇÃO E PESQUISA EM ADMINISTRAÇÃO, 31, 2007, Rio de Janeiro. Anais... Rio de Janeiro: ANPAD, 2007.

GARAY, Ângela Beatriz Scheffer. Voluntariado empresarial: modismo ou elemento estratégico. Revista de Administração, São Paulo, v.36, n.3, p.6-14, Jul. 2001.

GOLÇALVES, Rosana C. M. Grillo; PIRANI, Diego Camargo; BORGER, Fernanda Gabriela. Qualidade das informações sobre responsabilidade social divulgadas pelos bancos privados com ações listadas no índice de sustentabilidade empresarial da Bovespa. In: XXXI ENCONTRO DA ASSOCIAÇÃO NACIONAL DE PÓSGRADUAÇÃO EM ADMINISTRAÇÃO, 31, 2007, Rio de Janeiro. Anais... Rio de janeiro: ANPAD, 2007.

GRAJEW, Oded. Filantropia e Responsabilidade Social. Rio de Janeiro, 2002. Disponível em: < http://www.filantropia.org.br>. Acesso em: 13 jan, 2013.

KARKOTLI, Gilson. Responsabilidade Social Empresarial. Rio de Janeiro: Vozes, 2006.

LAGE, Allene Carvalho; MACHADO, Adriana Leite Costa Silva. Responsabilidade Social: uma abordagem para o desenvolvimento social: O Caso da CVRD. In: XXVI ENCONTRO DA ASSOCIAÇÃO NACIONAL DE PÓS-GRADUAÇÃO E PESQUISA EM ADMINISTRAÇÃO, 26, 2002, Florianópolis. Anais... Santa Catarina: ANPAD, 2002.

LEAL, Susana Cristina Henriques; REGO, José Arménio Belo da Silva. Reformulando a Dimensionalidade do Constructo de Responsabilidade Social das Empresas. In: XXXIV ENCONTRO DA ASSOCIAÇÃO NACIONAL DE PÓS-GRADUAÇÃO E PESQUISA EM ADMINISTRAÇÃO, 34, 2010, Rio de Janeiro. Anais... Rio de Janeiro: ANPAD, 2010.

MACHADO, Carla Mara. Contabilidade Ambiental: o papel da contabilidade na evidenciação de investimentos, custos e passivos ambientais. In: INSTITUTO ETHOS: Prêmio Ethos Valor. Vários autores. Responsabilidade social das empresas: 
a contribuição das universidades, v.2. São Paulo: Editora Fundação Petrópolis, 2003. p.273-311.

MALHOTRA, Naresh K. Pesquisa de marketing: uma orientação aplicada. 3.ed. Porto Alegre: Bookman, 2001.

MEDEIROS, João Bosco. Redação científica: a prática de fichamentos, resumos, resenhas.9. ed. São Paulo: Atlas, 2007.

MELO NETO, Francisco Paulo de; FROES, César. Gestão da responsabilidade social corporativa: o caso brasileiro. Rio de Janeiro: Qualitymark, 1999.

Responsabilidade social e cidadania emresarial: a administração do terceiro setor. 2 ed. Rio de Janeiro: Qualitymark, 2001.

MENDONÇA, Fernando. O que é Responsabilidade Social?. Fae Business, Curitiba, $n^{\circ}$ 9, p. 8-10, Set, 2004.

MORATELLI, Rafael Fachini; SOUZA, Maria José Barbosa de. A responsabilidade social no setor hoteleiro de Santa Catarina: uma aplicação da análise fatorial. In: XXX ENCONTRO DA ASSOCIAÇÃO NACIONAL DE PÓS-GRADUAÇÃO EM ADMINISTRAÇÃO, 30, 2006, Salvador. Anais... Salvador: ANPAD, 2006.

NAKAYAMA, Regina Mitiko; TEIXEIRA, Rivanda Meira. Ações de Responsabilidade Social com Relação ao Stakeholder: estudo de caso baseado nos indicadores Ethos na empresa $\mathrm{O}$ boticário. In: XXXIV ENCONTRO DA ASSOCIAÇÃO NACIONAL DE PÓS-GRADUAÇÃO E PESQUISA EM ADMINISTRAÇÃO, 34, 2010, Rio de Janeiro. Anais... Rio de Janeiro: ANPAD, 2010.

OLIVEIRA, Fábio Risério Moura de. Relações públicas e a comunicação na empresa cidadã. In: INSTITUTO ETHOS: Prêmio Ethos Valor. Vários autores. Responsabilidade social das empresas: a contribuição das universidades. v.1. São Paulo: Editora Fundação Petrópolis, 2002.

OLIVEIRA, Franciana Maria de; SILVA, João Augusto e. Estratégias de Responsabilidade Social corporativa: um estudo de caso sobre os 231 casos concretos do instituto Ethos. In: II ENCONTRO DE MARKETING DA ENANPAD, 2, 2006, Rio de Janeiro. Anais... Rio de Janeiro: ANPAD, 2006.

RICHARDSON, Roberto Jarry. Pesquisa Social: métodos e técnicas. 3 ed. São Paulo: Atlas, 2007.

RIZZI, Fernanda Basaglia. Balanço Social e ação de responsabilidade social nas empresas. In INSTITUTO ETHOS: Prêmio Ethos Valor. Vários autores. 
Responsabilidade social das empresas: a contribuição das universidades. v.1 São Paulo: Editora Fundação Petrópolis, 2002. p. 171-193.

TENÓRIO, Fernando Guilherme (org). Responsabilidade Social Empresarial: teoria e prática. 2 ed. Rio de Janeiro: FGV, 2006.

URSINI, Tarcila Reis; BRUNO, Giuliana Ortega. A gestão para responsabilidade social e o desenvolvimento sustentável. Fundação de Apoio a Tecnologia, São Paulo, p. 31-33, mar. 2003. 